\title{
Research on the Deformation Mechanisms of a Tunnel-Landslide System based on the Point Safety Factor of the Interface
}

\author{
Hong-gang $\mathrm{WU}^{1,3}$, Li-fang PAI ${ }^{2, *}$ \\ ${ }^{1}$ China Northwest Research Institute Co. Ltd.of CREC, China \\ 2. China Academy of Railway Sciences, China \\ ${ }^{3}$ China railway Landslide Engineering Laboratory, China
}

\begin{abstract}
Tunnel-landslide systems often cause slope deformation due to tunnel excavation along the slip surface. Based on the three-dimensional numerical calculation, the point safety factor of the interface (slip surface) of the tunnel-landslide system is defined as the ratio of the shear strength of the node to the sliding force. Taking an oblique tunnel-landslide system along the BAOJI-LANZHOU Passenger Dedicated Line as the main study objectives, the author determines the deformation mechanism of tunnel-landslide systems through the analysis of the distribution characteristics of the point safety factor of the interface. In this study, the conditions during excavation, conditions after construction, the interaction stability, deformation laws and possible failure modes, etc. of the tunnel-landslide system are seriously investigated. Our research indicates that the point safety factor of the interface can be taken as a quantitative assessment index of the tunnel-landslide system' s stability.
\end{abstract}

\section{Introduction}

Regarding the construction of highways and railways in mountainous areas, when tunnel construction cuts through a landslide it will affect the landslide' s stability. This results in the need for accurate evaluation, so measures can be taken to ensure the safety of the project and the stability of the landslide and tunnel engineering (Bandini et al. 2015; Mao and Zhou 2002; Barla et al. 2015). At present, some scholars have begun to pay attention to the study of tunnel excavation and landslide creep damage to tunnels (Causse et al. 2015; Ma 2003). In the processes of tunnel construction and operation, the tunnel and slope deformation have a close interaction, so the study of the deformation mechanism of the system should follow a principle of cooperation (Tao 2003). We establish the concept of a "tunnel-landslide system", with the main intention being to consider both the tunnel and landslide deformation characteristics of the development on their own as well as to consider the interaction between the two as a system in order to perform a comprehensive analysis of the system's deformation mechanism (Wu et al. 2012; Hungr and McDougall 2009).

The three-dimensional numerical method has been widely used in landslide analysis and calculation due to its advantages of accurate calculation. In terms of numerical analysis of landslide surge, Wang et al. used numerical calculation software to simulate the tsunami caused by chehalis lake landslide in Canada (Wang,2015). Surge generation, propagation process, and the impact of water to gravity dam were analyzed aiming at the problem of reservoir landslide surge influence on gravity dam (Chen,2016). Lan et al. summarized the research progress and development trend of numerical simulation methods of landslide and surge in reservoir area in recent years, including four stages: landslide instability, landslide, generation and propagation of surge (Lan,2016).

In terms of numerical analysis of landslide itself, some scholars performed numerical simulations of the 2011 deep-seated Akatani landslide in central Japan to understand the dynamic evolution of friction of the landslide (Yamada,2016). Zhang et al. simulated the landslide process in southern China by using continuum method, i.e. particle finite element method (PFEM) (Zhang,2015). In order to investigate the mechanism underlying the formation of landslides induced by irrigation in Heifangtai loess area, the Phase2 software was used for numerical simulation of the typical profile of Huangci landslide, and conditions of the landslide in natural and saturated states were respectively simulated (Lian,2018).

Through the above research, it is found that experts at home and abroad have done a lot of research on the landslide itself and the surge caused by it, but little research has been done on the point safety factor of the potential breaking point of the slope. In view of this, in order to intuitively analyze the slope potential failure point safety factor, e.g., the method proposed by Yang (2010) to calculate the safety factor, we must obtain the sliding point safety factor distribution of the plane and the overall safety coefficient, in order to use the

*Corresponding author's e-mail : 1072191799@qq.com 
calculation method to obtain a landslide stability evaluation of the three-dimensional system. But for a complex landslide surface, the sliding zone modeling with discrete hexahedral elements is not easy. Therefore, this paper gives a definition of the point safety factor in terms of the contact element, using FLAC3D to establish a numerical model for the surface element of the slide contact based on the contact surface stress obtained by numerical calculation combined with the safety coefficient of the Coulomb strength criterion definition. Taking an oblique tunnel-landslide system along the BAOJI-LANZHOU Passenger Dedicated Line as the main study objectives, we use contact analysis of the tunnel construction before and after landslide system (surface) distribution of the point safety factor to evaluate the effects of tunnel excavation on landslide stability.

\section{The Contact Point Safety Factor}

\subsection{Contact Surface Element Model}

In the FLAC3D program, the contact surface is composed of a series of triangular elements, each of which is defined by three nodes. The contact surface element is generally built on the surface of the solid element and is connected with the surface of the solid element. The node of the contact surface model is automatically formed by the vertex of the contact surface unit. When the contact relationship is formed between the solid element and the contact surface, this kind of contact is realized by the contact surface. The model parameters include normal stiffness, tangential stiffness, and sliding parameters (Peng 2007; Xu and Chen 2008).

The contact surface stress is defined on the node, and the unit is assigned to the node by its weight, which forms the characteristic area associated with the node that represents the entire contact surface, as shown in Figure 1.

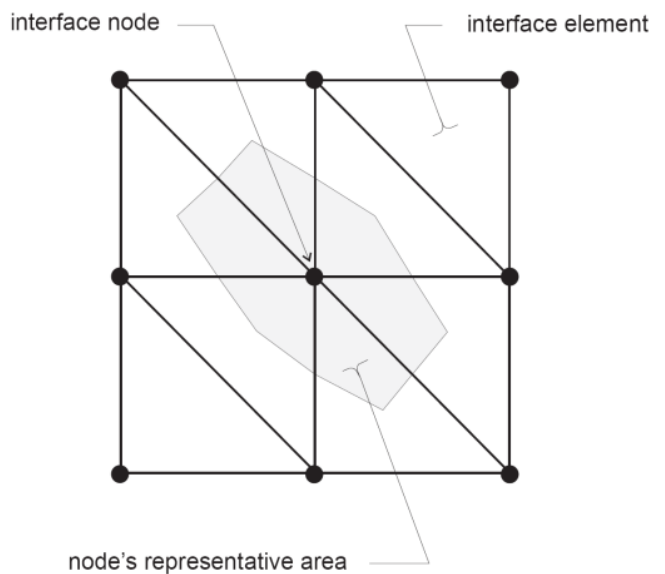

Figure. 1 Distribution of the representative areas relative to the interface nodes

The contact relationship is established on the external border of the contact surface (the target surface). The normal direction of the contact force is determined by the normal direction of the target surface. In each step of the calculation, we calculate the absolute target surfaces and the contact surfaces of the node to determine the invasive deformation and the relative tangential velocity of the contact surface in the constitutive equation, the calculated surface normal stress, and tangential stress vector. The joint constitutive model is defined by the linear Coulomb shear yield strength criterion, which can only be constrained by the shear stress on the contact surface. The effective normal stress increment is calculated according to the normal stiffness, tangential stiffness, tensile strength, shear bond strength, and shear expansion angle. Figure 2 shows the design of the node (P) constitutive model.

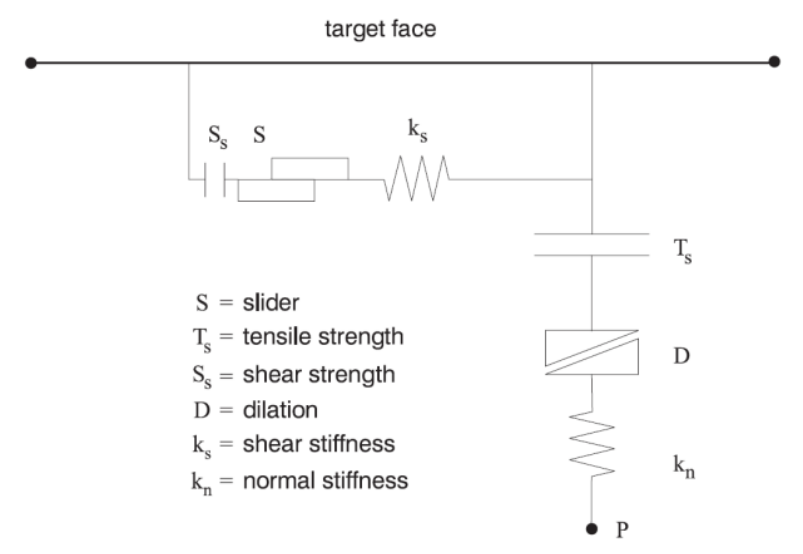

Figure. 2 Diagram of the node model

The elastic response of the contact surface is calculated at the moment, and the normal force and tangential force of the contact surface are calculated respectively as

$$
\begin{aligned}
& F_{n}{ }^{(t+\Delta t)}=k_{n} u_{n} A+\sigma_{n} A \\
& F_{s i}{ }^{(t+\Delta t)}=F_{s i}{ }^{(t)}+k_{s} \Delta u_{s i}{ }^{\left(t+\frac{1}{2} \Delta t\right)} A+\sigma_{s i} A
\end{aligned}
$$

Where $F_{n}^{(t+\Delta t)}$ is the normal force at time $(t+\Delta t)$ [force]; $F_{s i}{ }^{(t+\Delta t)}$ is the shear force vector at time $(t+\Delta t)$ [force]; $u_{n}$ is the absolute normal penetration of the interface node into the target face [displacement]; $\Delta u_{s i}$ is the incremental relative shear displacement vector [displacement]; $\sigma_{n}$ is the additional normal stress added due to interface stress initialization [force/displacement]; $\sigma_{s i}$ is the additional shear stress vector due to interface stress initialization; and $A$ is the representative area associated with the interface node [length2].

When the tangential force meets the Coulomb yield condition, a correction is adopted as follows:

$$
F_{s \max }=c A+\tan \varphi\left(F_{n}-p A\right)
$$

Where $c$ is the cohesion [stress] along the interface; $\varphi$ is the friction angle [degrees] of the interface surface; and $p$ is the pore pressure (interpolated from the target 
face), provided the keyword effective $=$ off has not been issued for the interface.

\subsection{Contact Surface Safety Factor Calculation Method}

At any moment, the normal stress and shear stress on the characteristic area of the joint can be obtained according to the normal force, the tangential force, and the characteristic area of the node. If the friction angle and cohesion within a given slip surface can be obtained at a node for shear strength

$$
\tau_{u}=c+\sigma_{n} \tan \varphi
$$

Then the point safety factor is defined as follows:

$$
F_{p}=\frac{\tau_{u}}{\tau}=\frac{c+\sigma_{n} \tan \varphi}{\tau}
$$

The point safety factor is calculated by export. By drawing the point safety factor distribution diagram we can intuitively see that the slope is the most dangerous location and determines the change in the whole safety factor calculation process. This method also allows us to predict the safety factor development trend and to take appropriate safety measures.

Although the contact point safety factor defines a simple form, the variable FLAC3D program cannot be directly defined by the interface nodes, thus the rendering process of the point safety factor distribution is more complex. In this study, we use FLAC3D and the Tecplot software to make full use of their advantages and create the drawing of the point safety factor distribution map.

The point safety factor calculation in the FLAC3D program is completed using the FISH language program. When the model to calculate the equilibrium state is used, we can calculate the contact point safety factor.

The memory address of any node can be set. We can use the following four steps to complete the calculation function. Step 1:Using the in_sstr (p_in, DOF) command we can get the node shear stress component (where DOF represents the coordinate component), after which we can obtain the node shear stress. Step 2:Using the in_nstr (in $\mathrm{p}_{3}$ ) command, we can get the node normal stress. Step 3:Using the in prop ( $\mathrm{p}$ in, string) command, where the strings are cohesion and friction, respectively, we can obtain the contact surface shear strength parameters. Step 4: We can calculate the point safety factor according to the formula.

We used Tecplot to create the point safety factor distribution map, but we needed to use FISH language program to obtain the output in a specific data format. The node information includes the node coordinate information and the node point security. The relationship between the unit and the node is that there is a node for each unit.

To obtain the node information output, you need to traverse all nodes. This requires that you pay attention to the FLAC3D in the contact surface addressing rules. The addressing of the contact surface is divided into three layers. The outermost layer is the contact surface group; the middle layer is the unit; and the innermost layer is the node. For each unit, we use ie vert ( $p$ ie, DOF) ( $p$ ie is the unit address, DOF by integers 1-3) to get the output node information and the node addressing. For each contact surface group, it is necessary to traverse all of the elements contained in it and to output all of the node information. The block diagram describing the process is shown in Figure 3.

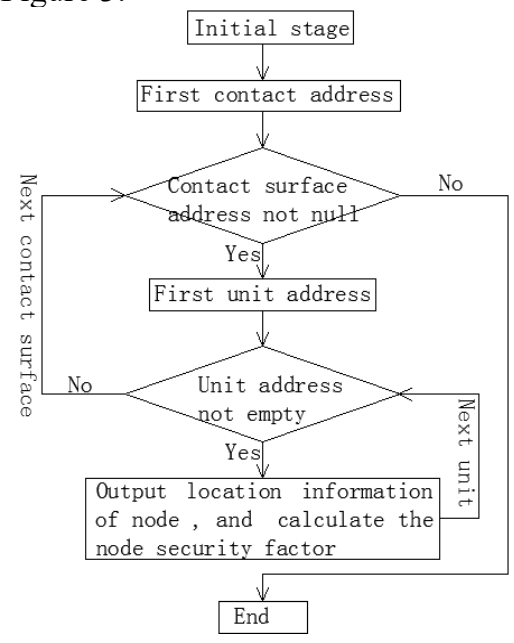

Figure. 3 Block diagram of data output

\section{Principle of the Spatial Deformation Mechanism of the Tunnel-Landslide System}

The determination of the stress state and the unit for calculating the sliding direction of the surrounding tunnel rock and the real surface unit can be divided into three steps. First, when the surrounding tunnel rock and the landslide material adopt an elastic constitutive model, we can calculate the initial stress field. Second, the sliding zone is analyzed using the Mohr-Coulomb constitutive model, while the surrounding tunnel rock, sliding body, and sliding bed are used in the constitutive model of the slope calculation to get the real stress state. Finally, the results of analysis steps one and two are used to obtain the surface element node in step two and the step displacement of A.

Accordingly, we can calculate the unit (sliding contact surface) of the point safety factor. The surrounding tunnel rock and the surface element stress state and slip direction are different, so the different sliding safety factors and units are generally not consistent. According to the distribution of the safety factor, the stability of the different parts of the landslide can be determined, and the deformation mechanism of the landslide can be analyzed. The point safety factor is less than or close to 1 for the parts of the surrounding tunnel rock and landslide in the first instability of the site, and is far greater than 1 for the relatively stable parts of the site. 


\section{Analysis of Application Example}

\subsection{Guo-Jia Tunnel-Landslide System}

We selected the Guo-Jia Tunnel on the BAOJILANZHOU Passenger Line to test the analysis model. It is located in Guo-Jia town in the northwestern part of Qinan County. It is a double tunnel; the tunnel mileage markers are IDK827+930 - IDK833+065; and the tunnel length is $5135 \mathrm{~m}$ with a maximum depth of $140 \mathrm{~m}$. The site features are as shown in Figure 4.

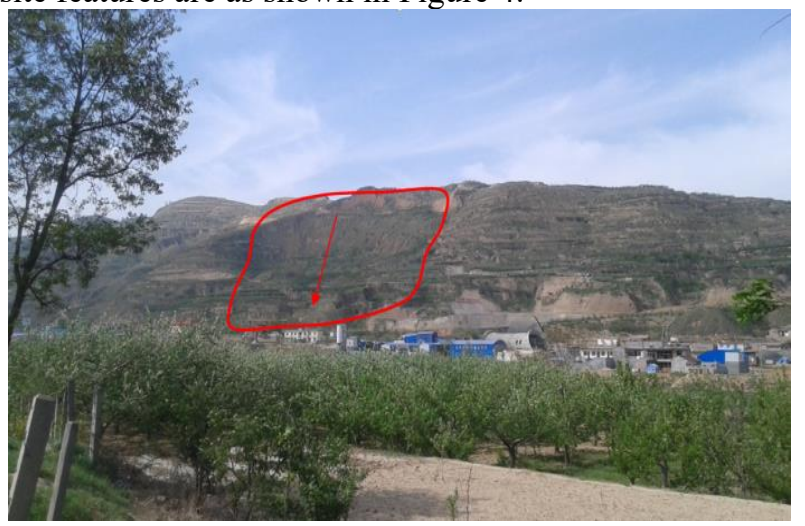

Figure. 4 Country tunnel morphology at the scene

The Guo-Jia tunnel is located at the top of the landslide between IDK828+190 - IDK828+570, IDK828+525 - IDK829+685, IDK828+900 IDK829+240, and IDK830+650 - IDK830+900 sections. The landslide occurred in clay loess, with a third of the residual material being mudstones. The layout and location of the main landslide section are as shown in Figure 5.

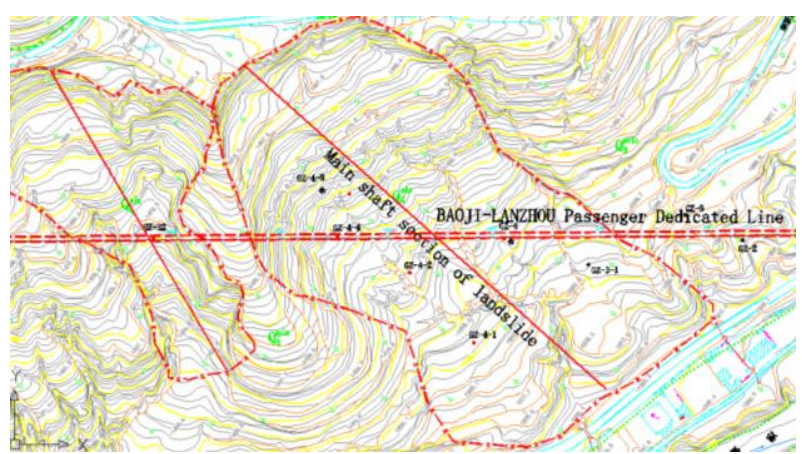

(a) The plane shaft

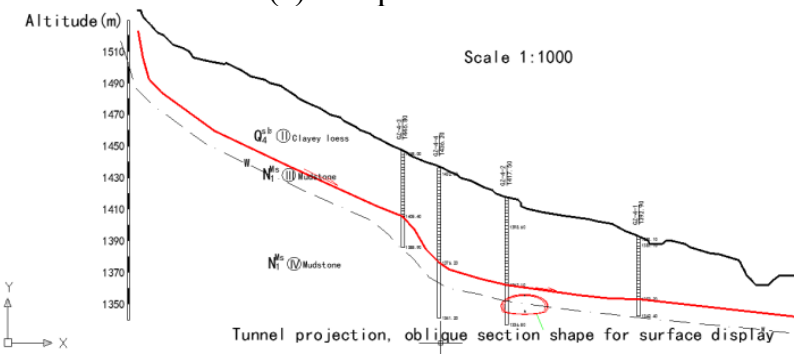

(b) The main section shaft

Figure. 5 The flat section of the slope cross section of the tunnel landslide

The main sliding zone of the landslide, between IDK $828+190$ - IDK $828+525$, is approximately $5 \mathrm{~m}$ away from the tunnel body, approximately $230 \mathrm{~m}$ away from the tunnel entrance, and approximately $40 \mathrm{~m}$ away from the air inlet hole. During construction the following safety measures should be taken: advanced supporting structures, narrow tunnel excavation footage, weakening blasting effect, strengthening supporting structure, and timely construction of tunnel lining; while the deformation of the surrounding rock is should be taken into account to ensure the stability of the landslide body.

\subsection{The Numerical Model of the Tunnel- Landslide System}

According to the related geological data, the Guo-Jia tunnel bedrock is IV-V grade rock. The sliding body material for clayey loess, according to the relevant experimental parameters and calculation experience, are as follows:

Table 1 . Model calculation parameters

\begin{tabular}{c|c|c|c|c|c}
\hline Material & $\begin{array}{c}\text { Density } \\
\left(\mathrm{kN} / \mathrm{m}^{3}\right)\end{array}$ & $\begin{array}{c}\text { Elastic modulus } \\
\mathrm{E}(\mathrm{GPa})\end{array}$ & $\begin{array}{c}\text { Poisson } \\
\text { ratio } \mu\end{array}$ & $\begin{array}{c}\text { Internal friction } \\
\text { angle } \varphi\end{array}$ & $\begin{array}{c}\text { Cohesion c } \\
(\mathrm{kPa})\end{array}$ \\
\hline Bedrock & 20 & 2 & 0.28 & $27^{\circ}$ & 200 \\
\hline Sliding body & 19 & 0.5 & 0.30 & $22^{\circ}$ & 25 \\
\hline
\end{tabular}

The contact surface (surface) material, according to the actual situation of the landslide in the limit equilibrium state, is determined through inversion combined with empirically determined calculations; and the results are as follows: normal stiffness $\mathrm{Kn}=500 \mathrm{MPa}$, tangential stiffness $\mathrm{Ks}=200 \mathrm{MPa}$, sliding friction angle $=15^{\circ}$, and cohesion $\mathrm{c}=12 \mathrm{kPa}$.

It is necessary to point out that because of the lack existing data as well as the lack of indepth of the research, the calculation parameters are not necessarily accurate. We will be more current research results, and then add the necessary supplementary survey information. Numerical analysis of the Guo-Jia tunnel, purely for the purpose of studying the impact of the construction of the tunnel on the landslide, is from a qualitative point of view to describe the analysis. The results of this analysis are mainly used for comparison of construction options. 
According to our research needs, we designed 3 kinds of working conditions. The first condition is the natural state. That is, a Tunnel without excavation construction. This is useful for analysis of the distribution of the surface point safety factor and for the determination of the distribution of the sliding point safety factor.

The second condition is a full tunnel excavation, i.e., the entire tunnel is excavated at once. This is useful for the analysis of the change in the surface point safety factor and for the determination of the most unfavorable influence of tunnel construction on landslides.

The third condition is a tunnel excavated in sections. This involves the excavation of the tunnel from both ends of the main shaft at the same time to reach the landslide. This is useful for analyzing the change in the surface point safety factor and for finding the tunnel construction footage at which there is an influence on the landslide.

\subsection{Numerical Simulation Process Analysis}

\subsubsection{Natural condition}

The accuracy of the numerical results is closely related to the accuracy of the model. Because of this, we first calculate the stress characteristics of the slope under natural conditions and the distribution characteristics of the safety factor of the slope to understand the stability of the slope under natural conditions.

Under natural conditions, i.e., when there is no tunnel excavation in slope, the load of the slope is only the weight of the slope's material (e.g., soil and rocks).

The plastic deformation distribution of the sliding body is shown in Figure 6, which refers to the deformation of the elastic state when the sliding body is a plastic material. As can be seen from Figure 6, the plastic deformation is mainly concentrated in the rear part of the landslide, and the maximum displacement is $18 \mathrm{~mm}$. The frontal displacement of the landslide is small, and the outlet displacement of the landslide is close to zero. The displacement contour is approximately perpendicular to the slide direction of the sliding body. From the point of view of the deformation of the landslide, the deformation and failure mode of the landslide is stimulated. The deformation characteristics of the landslide, simulated by numerical simulation, is consistent with the landform of the landslide in the field. The posterior boundary of the landslide has the characteristic of the chair-like terrain. The front part of the landslide body has a bulging feature, which is extruded by landslide sliding extrusion. This indicates that a driving type of instability has occurred in the past, which is consistent with the calculation results.

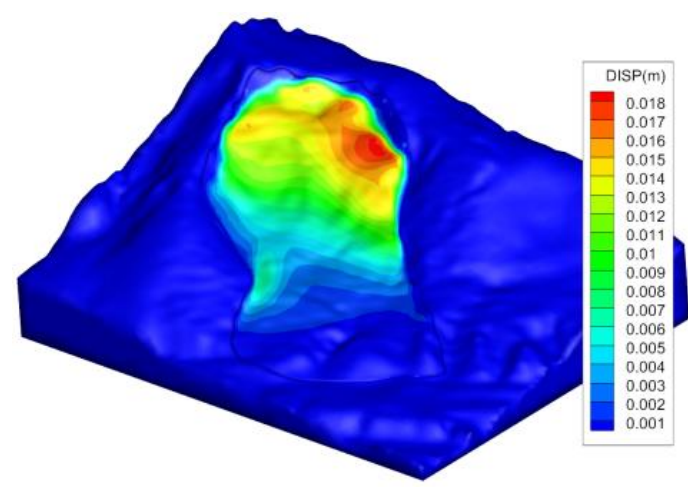

Figure. 6 The distribution of the plastic displacement of the sliding body

The distribution of the safety factor of the landslide is shown in Figure 7. From the point of view of this distribution, the safety factor of the rear and the two sides of the landslide is small (close to 1), indicating that the site is in the limit equilibrium state. While the safety factor of the front of the landslide is generally greater than 1.8, especially in the individual areas close to 2.0. The data shows that the stability of these parts is better, which is the sliding section of the slide. The internal point of the slope safety coefficient is revealed from the longitudinal section of the tunnel and the cross section of the main landslide, the landslide safety factor is smaller near the surface (Figure $7 \mathrm{~b}$ ). The shallow slope safety coefficient shows that for landslide failure, the failure mechanism is characterized by smooth sliding and from the bottom up in the upper sliding body there is a loss of traction in the sliding stability. Therefore, the stability of the sliding surface restricts the overall stability of the landslide. As a follow-up study, we should pay special attention to the stability of the slip surface. From the point of view of the landslide (Figure 7c), the distribution of the spindle section's point safety factor is revealed. From this, we can clearly judge the main landslide sliding and anti-sliding sections. The safety coefficient is close to the limit of the state of the section for the main sliding section; while the front point safety factor is more than 1 for the anti-sliding section. This also reveals the driving mechanism of the landslide.

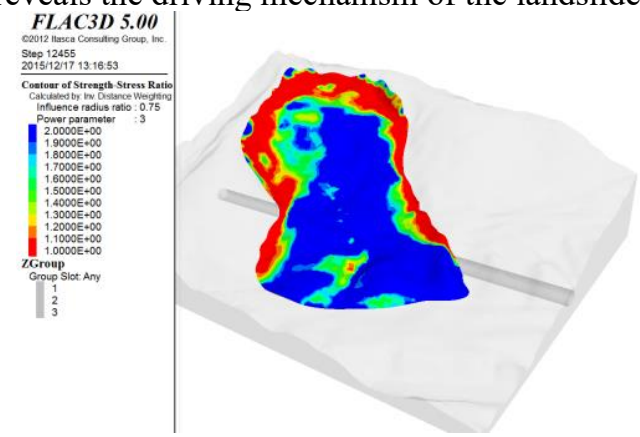

(a) Sliding body 


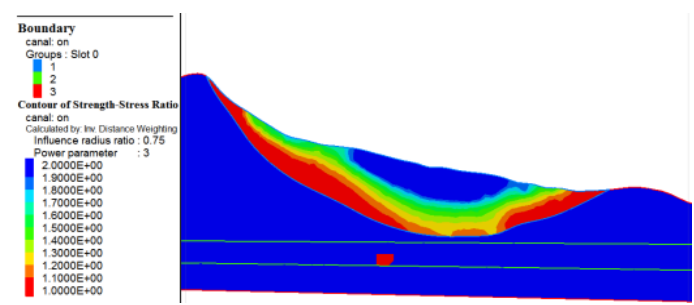

(b) View along the main axis of the tunnel section

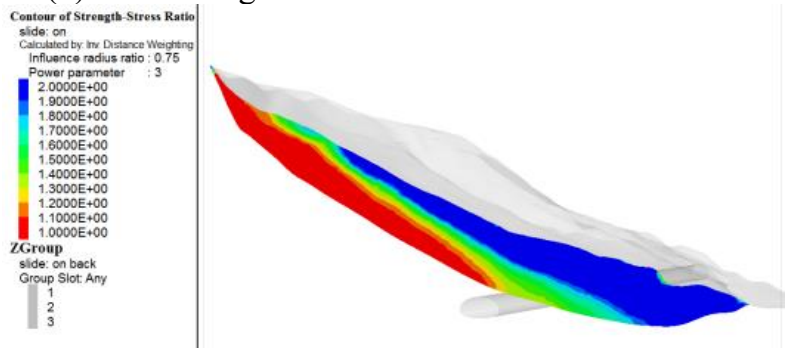

(c) View along the main axis of the landslide

Figure. 7 Distribution of safety factor of the sliding body

Figure 8 shows the distribution of the surface point safety factor and more clearly reveals the stability of the landslide on the slip surface of the partition. It can be seen that most of the rear surface is at the limit of the equilibrium state (safety coefficient is $\sim 1$ ), so it is a sliding landslide. Only for the small front area is stability good (point safety factor is $>1$ ), so this has become the sliding section of the landslide. Figure 9 shows the surface of the distribution of the shear stress and the distribution of the normal stress. It can be seen that on the rear surface, shear stress and normal stress are larger and smaller, respectively. While on the front surface, the shear stress is relatively small and the normal stress is fairly large. The particularity of the slope topography determines the distribution of stress on the sliding surface, and thus, determines the slip point safety factor, and consequently determines the stability of the landslide. Therefore, the stability of the landslide is decided by the special geomorphology and geological conditions of the landslide.

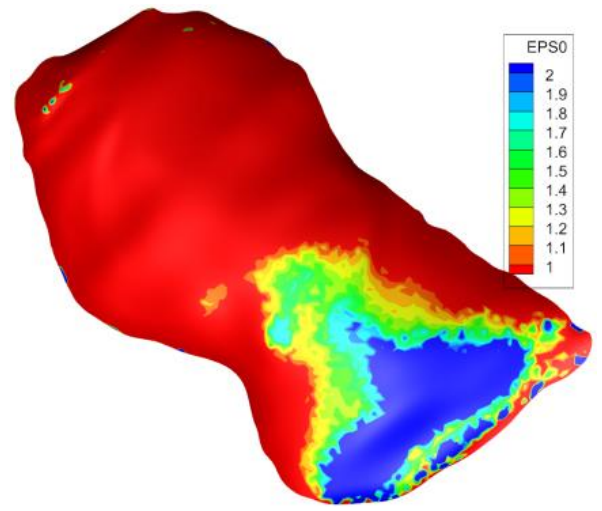

Figure. 8 Surface point safety factor distribution

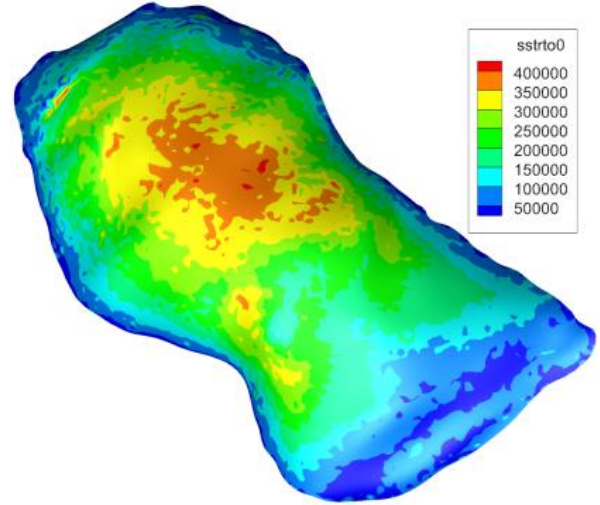

(a) Surface shear stress distribution

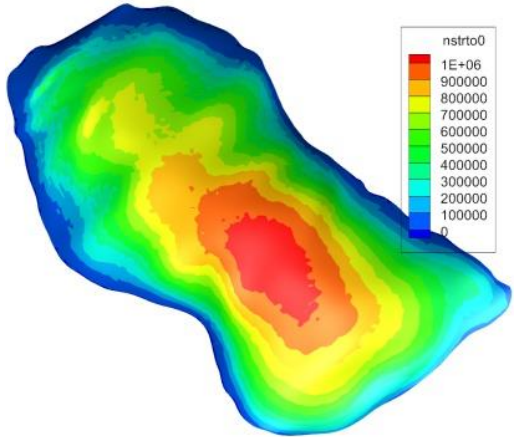

(b) Normal stress distribution

Figure. 9 Surface stress distribution

From the above discussion, it can be concluded that the landslide has obvious slip promoting characteristics and the results of the calculation and landslide deformation indicators are consistent, indicating that the numerical simulation of the modeling process is correct and that the calculation parameters are more reasonable.

\subsubsection{Tunnel excavation}

First, the landslide stability of the most unfavorable state is analyzed, i.e., the full excavation state of the tunnel.

For the visual expression of the calculated results, only changes in the surface point safety factor of the listed values are made, and the surface shear stress and normal stress change value. Local amplification is shown in Figures 10 and 11.

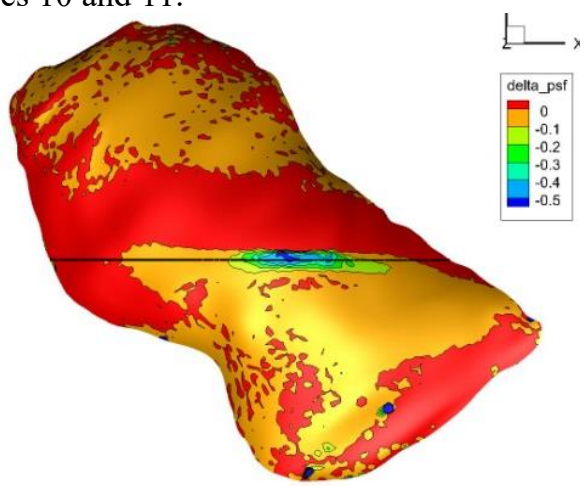

(a) Global surface 


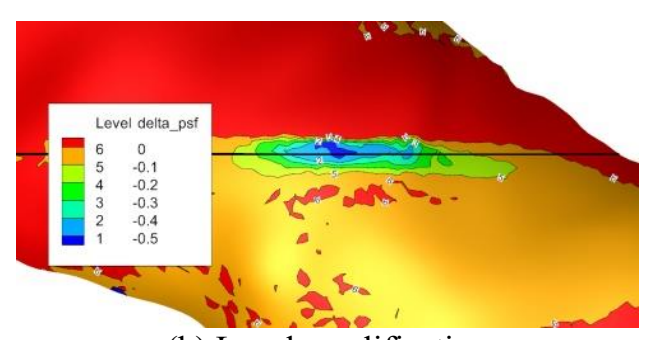

(b) Local amplification

Figure. 10 Variation in surface point safety factor

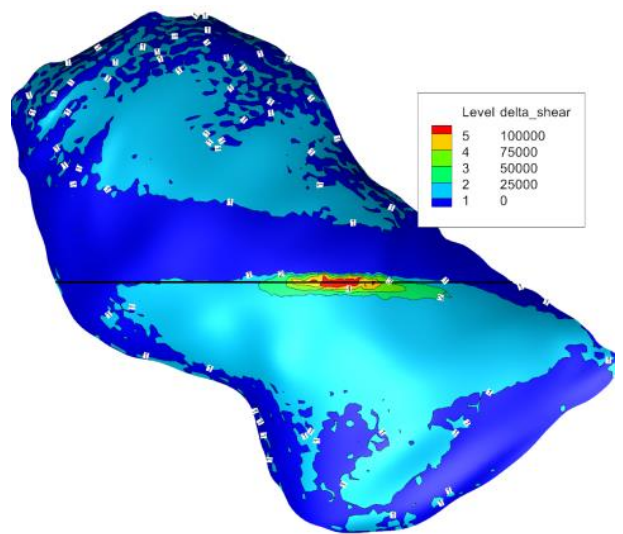

(a) Global surface

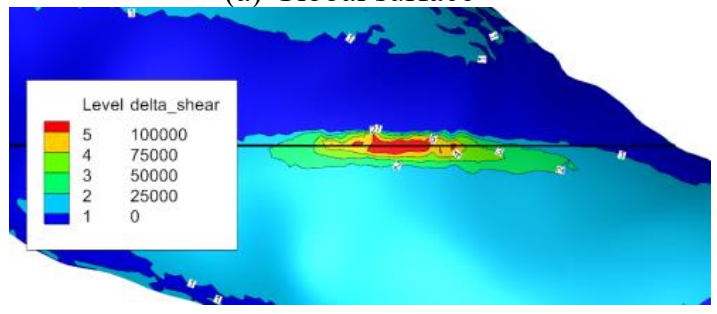

(b) Local amplification

Figure. 11 Changes in the surface shear stress

Figure 12 shows the tunnel excavation in all conditions, the sliding surface of the local area is significant with a maximum decrease of 0.5 in the point safety factor. The area of the point safety factor decreases linearly along the tunnel's axial direction, the decrease in the middle part is the most obvious, with a maximum of 0.5 . To both sides of the extension of life, the amplitude gradually decreases. When the decrease is due to the tunnel vault from the surface near the tunnel excavation, the decrease of the surface point safety factor is greater. When the vertical distance from the tunnel vault to the surface is more than $10 \mathrm{~m}$, the effect of the tunnel excavation on the surface point safety factor is not obvious.

The sliding surface, as shown in Figure 12, shows the distribution of the stress reduction should be consistent with the change in the point safety factor of the slip surface; the shear stress increased; and the normal stress decreased. The normal stress is linear along the axial distribution of the tunnel. The more the position of the point on the sliding surface is closer to the tunnel crown, the greater the variation of the normal stress. If the position of the point on the sliding surface and tunnel vertical distance of more than $10 \mathrm{~m}$, the normal stress changes in the performance is not obvious.

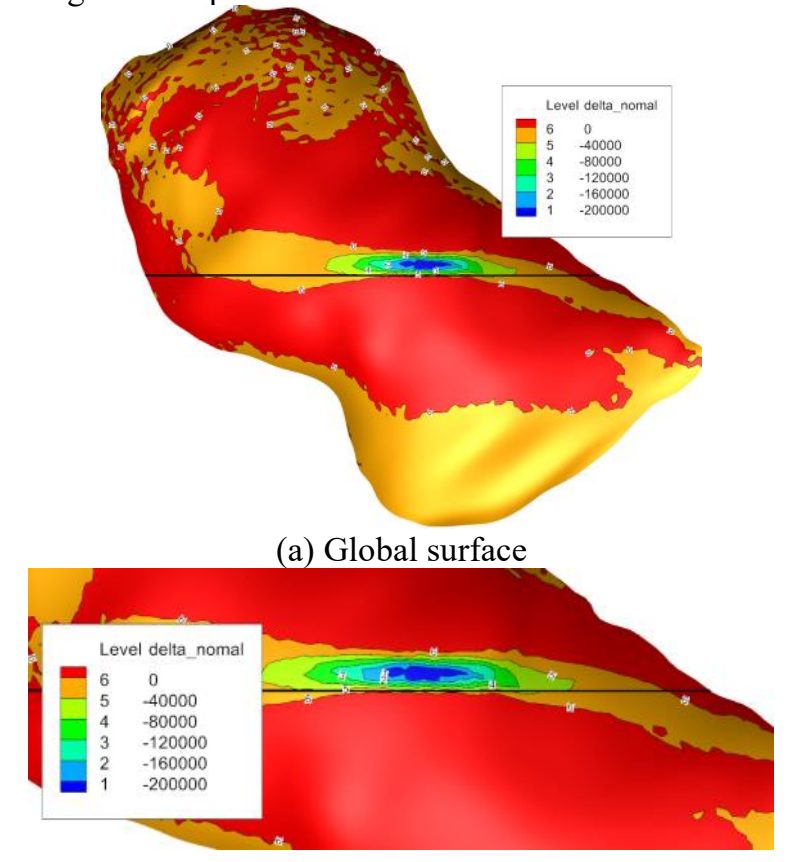

(b) Local amplification

Figure. 12 Variation in normal stress of the slip

\subsubsection{The area within $70 \mathrm{~m}$ from the ends of the excavation}

When the tunnel is fully excavated, the influence of the sliding surface is very obvious. The sequence of tunnel excavation is from the outside of the sliding body, then moving gradually closer to the middle part of the sliding body. This section discusses the influence of the construction stage of the tunnel.

Based on this model, according to the conditions of excavation from both ends to the interior, with a $5 \mathrm{~m}$ gradient and a gradual increase in the length of the excavation, the stress field and the surface point safety coefficients can be calculated. The calculation results show that when the excavation extends more than $70 \mathrm{~m}$ inward from the ends of the tunnel, the safety coefficient of the sliding surface begins to exhibit an obvious change.

Calculation model for the area within $70 \mathrm{~m}$ of the ends of the tunnel, with only the middle of the tunnel unexcavated, is shown in Figure 13.

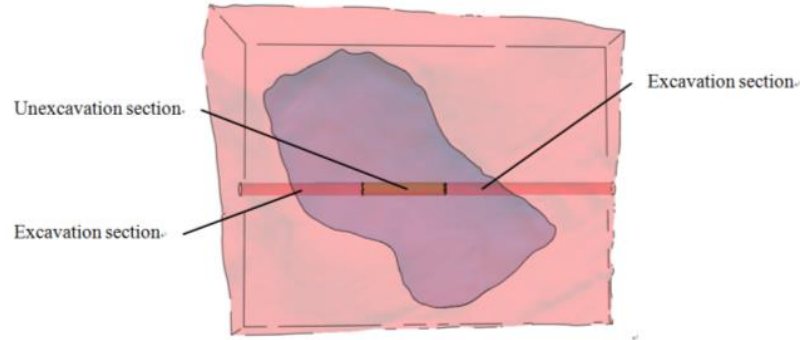

Figure. 13 The stage that affects the surface of the tunnel excavation 
At this time, the slip point safety factor changes, as shown in Figure 14. Obviously, the decrease in the point safety factor is smooth and is located on the right side of the tunnel, which is close to the outlet in the side cut. At this point on the excavation face, the vertical distance from the surface of the tunnel is about $10 \mathrm{~m}$. The surface shear stress and the stress change, as shown in Figure 15.

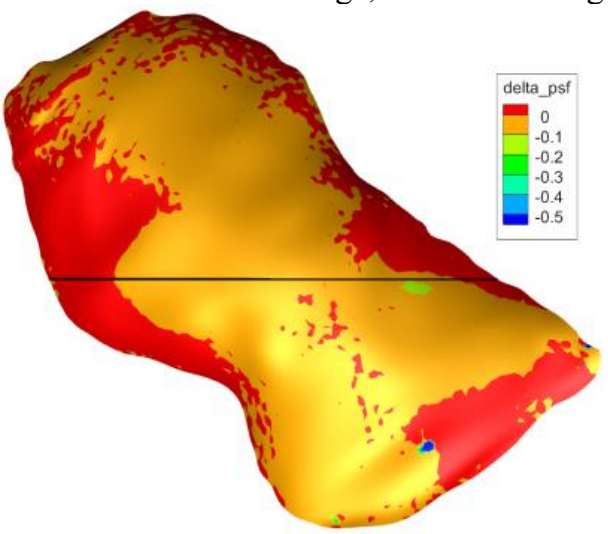

(a) Global surface

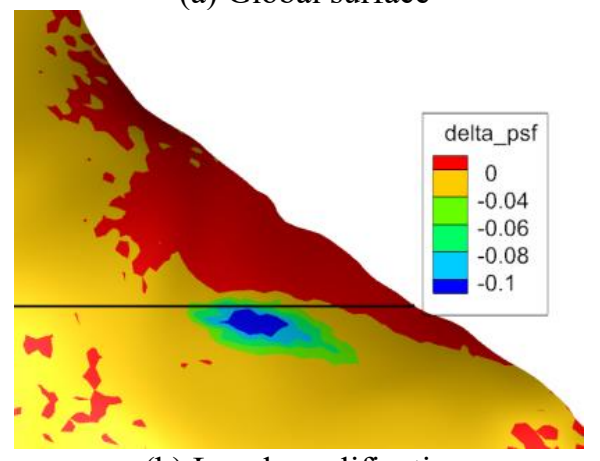

(b) Local amplification

Figure. 14 Variation in the surface point safety factor

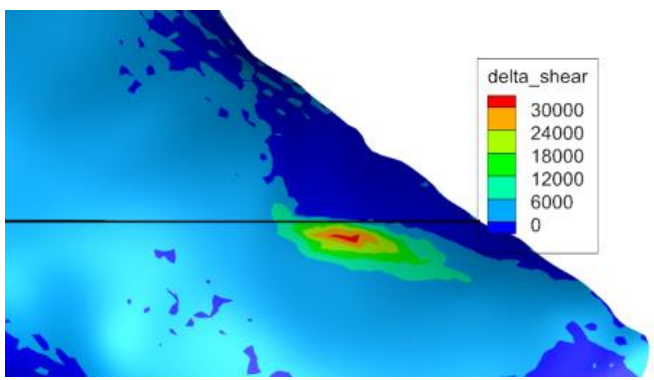

(a) Shear stress variation

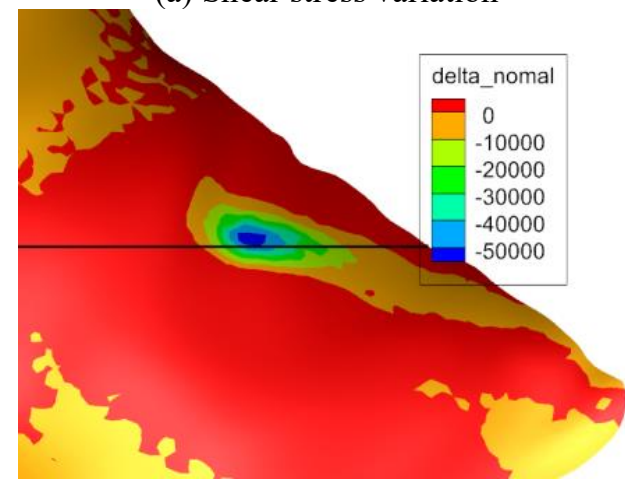

(b) Positive stress changes

Figure. 15 Changes in the slip surface stress state

\section{Conclusions}

(1) Analysis of the system cannot be done without the space deformation mechanism of the tunnel-landslide system. Based on the calculation results of the $3 \mathrm{D}$ numerical model, we can define the contact surface (surface) safety coefficient and determine the deformation mechanism of the system by analysis of the distribution characteristics of the point safety factor. When the surrounding rock of the tunnel and the surface unit are in a plastic state, this model indicates that the most dangerous section of the tunnel in terms of normal stress and shear stress can yield criterion that can be used to judge the degree of stability of different parts of the landslide according to the distribution of the point safety factor. A safety factor of less than or near 1 for the tunnel, indicates the site of the first instability of the surrounding rock and landslide.

(2) The calculation for the Guo-Jia tunnel shows that the landslide system has characteristics of driven slip. The front surface has good stability (safety coefficient $>$ $1)$, so this is the anti-sliding section of the landslide. According to the vertical projection, the tunnel's axial direction passes through the anti-sliding section of the landslide body. The whole excavation tunnel is probably the most unfavorable situations. When the distance from the tunnel vault to the surface near the point safety factor decreased, the safety coefficient of the surface area decreased along the tunnel's axial point of linear distribution. When the vertical distance from the tunnel vault to the surface is greater than $10 \mathrm{~m}$, the safety coefficient did not change significantly. In the excavation section of the tunnel, the tunnel face being located under the sliding surface does not necessarily affect the stability of the landslide. Only when the distance from the tunnel to the surface is close to $10 \mathrm{~m}$ will the tunnel construction be affected by the stability of landslide. This stability effect initially occurs at the side nearest the landslide shear outlet.

\section{References}

1. Bandini A., Berry P., Boldini D. (2015) Tunneling-induced landslides: the Val di Gambro tunnel case study. Engineering Geology 196(9): 71-87.

2. Barla G., Debernardi D., Perino A. (2015) Lessons learned from deep-seated landslides activated by tunnel excavation. Geomechanics and Tunnelling, 8(5): 394-401.

3. Causse L., Cojean R., Fleurisson, J.A. (2015) Interaction between tunnel and unstable slopeinfluence of time-dependent behavior of a tunnel excavation in a deep-seated gravitational slope deformation. Tunnelling and Underground Space Technology 50(8): 270-281.

4. Chen, J.Y., Jing, L.I., Qiang, X.U., et al. (2016) Numerical simulation of Landslide surge and its effects on gravity dam[J]. Journal of Zhejiang University (Engineering Science). 
5. Hungr O., McDougall S. (2009) Two numerical models for landslide dynamic analysis. Computers and Geosciences 35(5):978-992.

6. Lian B., Wang X., Zhu R., et al. (2018) A numerical simulation study of landslides induced by irrigation in Heifangtai loess area-A case study of Huangci[J]. IOP Conference Series Earth and Environmental Science, 108(3):032064.

7. Zhao, L.H., Hou, S.C., Mao, J. (2016) Review of numerical simulation of landslides and surges in reservoir districts[J]. Advances in Science and Technology of Water Resources.

8. Mao, J.Q., Zhou, D.P., (2002) Deformation analysis of landslide-tunnel interaction[J]. Journal of Southwest Jiaotong University, 37( 4) : 371376. (In Chinese)

9. Ma, H.M., (2003) Discussion on Problems of Slope Disaster and Tunnel deformation[J]. Chinese Journal of Rock Mechanics and Engineering, 22:2719-2724. (In Chinese)

10. Peng, W.B., (2007) FLAC3D practical tutorial [M]. Beijing: Mechanical Industry Press. (In Chinese)

11. Tao, Z.P., (2003) Study on Tunnel Deformation Mechanism at Landslide Site and Disaster Predicting and Controlling[D]. Chengdu,Southwest Jiaotong University. (In Chinese)

12. Wu, H.G., Wu, D.Y., Ma, H.M., etc (2012) research on type of tunnel landslide system and tunnel deformation mode [j]. chinese journal of rock mechanics and engineering,31 (supper2) 3632-3642. (In Chinese)

13. Wang, J., Ward, S.N., Xiao, L. (2015) Numerical simulation of the December 4, 2007 landslidegenerated tsunami in Chehalis Lake, Canada[J]. Geophysical Journal International, 201(1):372376.

14. Xu, D.P., Chen, Y.M., (2008) FLAC/FLAC3D foundation and engineering example $[\mathrm{M}]$. Beijing: China Water Conservancy and Hydropower Press. (In Chinese)

15. Yang, T., Zhou, D.P., Ma, H.M., et al (2010) Point safety factor method for stability analysis of landslide[J].Rock and Soil Mechanics, (3) :971975.

16. Yang, T., You, X., Qin, Y.T., et al (2010) Application of point safety factor to study on spatial sliding mechanism of landslide[J]. Journal of Southwest Jiaotong University,45 (5) : 794799. (In Chinese)

17. Yamada, M., Mangeney, A., Matsushi, Y., et al. (2016) Estimation of dynamic friction of the Akatani landslide from seismic waveform inversion and numerical simulation[J]. Geophysical Journal International:ggw216.

18. Zhang, X., Krabbenhoft, K., Sheng, D., et al. (2015) Numerical simulation of a flow-like landslide using the particle finite element method[J]. Computational Mechanics, 55(1):167177. 